Research Paper

\title{
The GHS-R Blocker I-[Lys3] GHRP-6 Serves as CCR5 Chemokine Receptor Antagonist
}

\author{
Kalpesh Patel ${ }^{\ddagger}$, Vishwa Deep Dixit ${ }^{\dagger}$, Jun Ho Lee, Jie Wan Kim, Eric M. Schaffer ${ }^{\star}$, Dzung Nguyen\# and \\ Dennis D. Taub ${ }^{凶}$
}

Laboratory of Molecular Biology and Immunology, National Institute on Aging, Intramural Program, NIH, 251 Bayview Boulevard, Baltimore, MD. 21224, USA.

‡Present Address: Sidney Kimmel Comprehensive Cancer Center, Johns Hopkins University, Baltimore, MD. 21231.

† Present Address: Laboratory of Neuroendocrine-Immunology, Pennington Biomedical Research Center, LSU System, Baton Rouge LA. 70808.

${ }^{*}$ Present Address: BioSensors Branch, RDCB-DRB-S, Edgewood Chemical Biological Center, APGEA, MD. 21010.

\# Present Address: BioLegend, 1180 Roselle St., San Diego, CA. 92121.

Corresponding author: Dennis D. Taub, PhD, Clinical Immunology Section, Laboratory of Molecular Biology and Immunology, National Institute on Aging-Intramural Research Program, NIH, 251 Bayview Boulevard, Baltimore, MD, 21224. Phone: (410) 558-8428; Fax: (410) 558-8284; E mail: Taubd@grc.nia.nih.gov.

() Ivyspring International Publisher. This is an open-access article distributed under the terms of the Creative Commons License (http://creativecommons.org/ licenses/by-nc-nd/3.0/). Reproduction is permitted for personal, noncommercial use, provided that the article is in whole, unmodified, and properly cited.

Received: 2011.10.26; Accepted: 2011.11.17; Published: 2011.11.18

\begin{abstract}
[D-Lys3]-Growth Hormone Releasing Peptide-6 (DLS) is widely utilized in vivo and in vitro as a selective ghrelin receptor (GHS-R) antagonist. This antagonist is one of the most common antagonists utilized in vivo to block GHS-R function and activity. Here, we found that DLS also has the ability to modestly block chemokine function and ligand binding to the chemokine receptor CCR5. The DLS effects on RANTES binding and Erk signaling as well as calcium mobilization appears to be much stronger than its effects on MIP-I $\alpha$ and MIP-I $\beta$. CCR5 have been shown to act as major co-receptor for HIV-I entry into the CD4 positive host cells. To this end, we also found that DLS blocks M-tropic HIV-I propagation in activated human PBMCs. These data demonstrate that DLS may not be a highly selective GHS-R Ia inhibitor and may also effects on other G-protein coupled receptor (GPCR) family members. Moreover, DLS may have some potential clinical applications in blocking HIV infectivity and CCR5-mediated migration and function in various inflammatory disease states.
\end{abstract}

Key words: MIP-1 $\alpha$, MIP-1 $\beta$, RANTES, CCR5; HIV-1, Ghrelin, GHRP-6, GHS-R1a, Inflammation, Cancer.

\section{Introduction}

Chemokines are small peptides that are known to exert potent regulatory effects on migration and activation of various immune and non hematopoietic cells via ligation to their seven transmembrane G-protein coupled receptors [1, 2]. CCR5 serves as an endogenous ligand for CC chemokines, MIP-1 $\alpha / C C L 3$, MIP-1 $\beta / C C L 4$ and RANTES/CCL5. $\mathrm{CC}$ chemokine receptor 5 (CCR5) regulates trafficking and effector functions of memory/effector T-lymphocytes, macrophages, and immature dendritic cells [3]. Interestingly, chemokine receptors CXCR4 and CCR5 have attracted substantial interest because they form portals of cellular entry for the human immunodeficiency viruses (HIV-1 and HIV-2) and related simian or feline retroviruses[4]. While all the HIV-1 strains require CD4 to enter and infect cells, 
some use the chemokine receptor CXCR4 (T-tropic/X4 strain or syncytium-inducing viruses), or CCR5 (M-tropic/R5 strain or non-syncytium-inducing viruses) and some can utilize either coreceptor (R5X4 strains) for these purposes. Several HIV-1 coreceptor antagonists have been recently discovered and are being utilized in human clinical trials[5]. In addition to pathogenesis of HIV, CCR5 receptors have been implicated in motility [2]. Given the involvement of CCR5 in HIV and inflammation these receptors have emerged as potential targets for therapeutic intervention [4].

Growth hormone secretagogue receptor (GHS-R) belongs to a seven transmembrane GPCR family and serves as an endogenous ligand for stomach derived hormone ghrelin [6, 7]. Growth hormone releasing peptide-6 (GHRP-6) is one of earliest synthetic peptidyl GHS-R agonist utilized to study the functions of GHS-R prior to the discovery of the endogenous ligand ghrelin[8]. Modification of GHRP-6 (H-His-D-Trp-Ala-Trp-D-Phe-Lys-NH2) from alanine to D-lysine resulted in a GHS-R antagonist D-[Lys3]GHRP-6 (H-His-D-Trp-D-Lys-Trp-D-PheLys-NH2). Currently, the D-[Lys3]GHRP-6 (DLS) is utilized in in vitro and in vivo studies as a selective GHS-R antagonist[7] (Figure 1). However, no studies have yet addressed the specificity and efficacy of this compound in human $\mathrm{T}$ lymphocytes, $\mathrm{T}$ cell lines, PBMCs or other immune cell subsets. Given the potent effects of natural GHS-R ligand ghrelin on human
$\mathrm{T}$ cell responses [9], we evaluated the specificity of DLS and its potential interactions with other immunologically relevant GPCRs of chemokine family and present evidence that DLS also modestly antagonizes CCR5 receptor signaling, function and HIV-1 coreceptor activity. The most important finding in these studies if not the discovery of DLS as a potential HIV antagonist (as other more potent and selective chemokine receptor antagonist are more efficient and selective) but that the DLS antagonist is not as highly selective to GHS-R1a as originally thought and may have some impact on other G-protein coupled receptors (GPCRs) including chemokine receptors.

\section{Materials and Methods}

\section{Cell culture and Cell lines}

CEM.NKR_CCR5, 3T3.T4.CCR5, CCR5 receptor

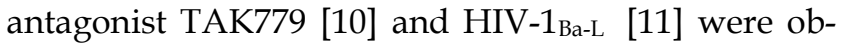
tained from the AIDS Research and Reference Reagent Program, Division of AIDS, NIAID, NIH ( CEM.NKR-CCR5 from Dr. Alexandra Trkola, 3T3.T4.CCR5 from Dr. Dan R. Littman, HIV-1 Ba-L from Dr. Suzanne Gartner, Dr. Mikulas Popovic and Dr. Robert Gallo). Pheresis packs were prepared from 4 healthy male donors between 18 and 45 years age for the isolation of PBMCs. PBMCs were obtained by Ficoll-Hypaque density centrifugation. PBMCs were activated with PHA.

\section{[D-Lys3]-Growth Hormone Releasing Peptide-6 (DLS)}

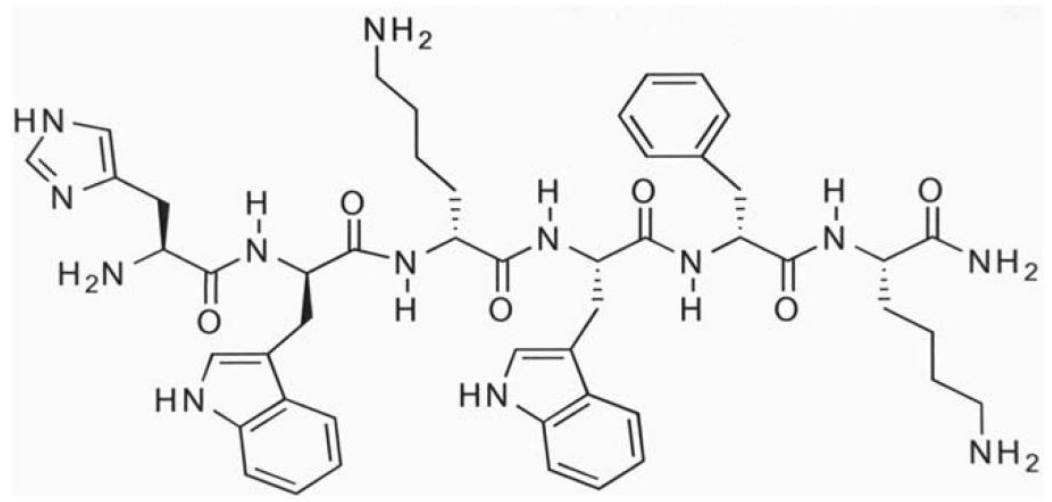

H-His-D-Trp-D-Lys-Trp-D-Phe-Lys-NH2

Figure I. Structure of DLS. 


\section{Intracellular calcium mobilization}

Measurement of intracellular calcium release in response to MIP- $1 \alpha(60 \mathrm{nM}), \mathrm{MIP}-1 \beta(60 \mathrm{nM})$ and RANTES $(10 \mathrm{nM})$ were performed as described previously and as described in the legends [12]. CEM.NK ${ }^{\mathrm{R}}-\mathrm{CCR} 5$ cells were incubated in PBS containing $5 \mathrm{mM}$ Fura-2 acetoxymethyl ester (Molecular Probes) for 30 minutes at room temperature. The cells were subsequently washed and then resuspended at 1 $x 10^{6}$ cells per $\mathrm{ml}$ in PBS. A total of $2 \mathrm{ml}$ of the cell suspension was placed in a continuously stirring cuvette at room temperature in an LS50B spectrophotometer (Perkin-Elmer, Wellesley, Massachusetts, USA). Cells were treated with MIP-1 $\alpha$ (60nM), MIP-1 $\beta$ (60nM)and RANTES (10nM) and along with DLS (Sigma-Aldrich) at various concentrations. Fluorescence was monitored at $\lambda_{\mathrm{ex} 1}=340 \mathrm{~nm}, \lambda_{\mathrm{ex} 2}=380 \mathrm{~nm}$, and $\lambda_{\mathrm{em}}=510 \mathrm{~nm}$. The data are presented as the relative ratio of fluorescence excited at 340 and $380 \mathrm{~nm}$.

\section{Fluorokine ligand binding}

Fluorokine binding assay was performed as described previously and in the Figure legends [13]. Briefly, biotinylated MIP- $1 \alpha$, MIP- $1 \beta$ and RANTES (Fluorokine; R\&D Systems) staining was performed according to R\&D Systems' protocols, with slight modifications. The control or treated CEM.NKR-CCR5 cells were resuspended in PBS at $4 \times 10^{6} \mathrm{cells}$ per $\mathrm{ml}$. $25 \mu \mathrm{l}$ of cells were treated with $1 \mu \mathrm{g}$, $4 \mu \mathrm{g}$ or $16 \mu \mathrm{g}$ of DLS at $37^{\circ} \mathrm{C}$ for $30 \mathrm{~min}$, then mixed with $20 \mu \mathrm{l}$ of 2.5 $\mu \mathrm{g} / \mathrm{ml}$ biotinylated SDF- $1 \alpha$ and incubated at $4^{\circ} \mathrm{C}$ for 1 h. $20 \mu \mathrm{l}$ fluorescein-conjugated avidin $(10 \mu \mathrm{g} / \mathrm{ml})$ was added to the cells and incubated for an additional 30 $\min$ at $4^{\circ} \mathrm{C}$. After incubation, cells were washed with 1x RDF-1 buffer (R\&D Systems) and then fixed with $2 \%$ paraformaldehyde in PBS before being analyzed on a FACScan (BD Biosciences).

\section{Western blot analysis}

As described here and in the Figure legends, control and treated 3T3.T4.CCR5 cells were lysed in RIPA buffer supplemented with protease and phosphatase inhibitor cocktail (Sigma-Aldrich, St. Louis, $\mathrm{MO})$ and protein concentrations of cell lysates were determined by Bradford assay. Protein lysates $(30 \mu \mathrm{g})$ were diluted with sample buffer and separated on 4-20\% Tris $\mathrm{HCl}$ SDS-polyacrylamide gels (Biorad, Hercules, CA) and electrophoretically transferred to nitrocellulose membranes (Schleicher \& Schuell). The blots were then incubated with rabbit anti-phospho-P42 and pERK (Cell Signaling, Beverly, MA). Immune complexes were visualized by incuba- tion with either an anti-rabbit or an anti-mouse HRP-conjugated secondary antibody (Amersham, Piscataway, NJ). The immunoreactive band was visualized by enhanced chemiluminescence (Perkin-Elmer).

\section{HIV infection}

HIV-1 $1_{\text {Ba-L }}$ was propagated in activated PBMC cells and p24 was measured in sup by ELISA (SAIC, Frederick, USA). PBMCs were activated by $5 \mu \mathrm{g} / \mathrm{ml}$ phytoheamagglutinin (PHA) and 10units/ml IL2 for three days, on day three, cells were washed and resuspended as one million per $\mathrm{ml}$ in cRPMI medium. Activated PBMCs were treated with various concentrations of DLS and TAK779 at 37C for 30 minutes. Then HIV-1 $1_{\text {Ba-L }}$ was added to a final concentration of p24 of $10 \mathrm{ng} / \mathrm{ml}$. Incubate at $37 \mathrm{C}$ for three hours and wash cells to remove virus, resuspend cells as $5 \mathrm{e}+5$ cells per $\mathrm{ml}$, add antagonist and plate as triplicates in 24 well plate. Collect sup at day 3, 6 and 9 and measure p24 level in sup by ELISA. Graphs show \% of p24 level over virus only controls at day 6 and day 9 .

\section{Results}

\section{D-Lys3-GHRP-6 inhibits MIP-I $\alpha$, MIP-I $\beta$ and RANTES induced intracellular calcium release from CEM.NKR-CCR5 cells}

Ligation of seven transmembrane GPCRs typically results in calcium mobilization from the intracellular stores by generation of inositol triphosphate. MIP- $1 \alpha$, MIP- $1 \beta$ and RANTES binding to CCR5 is known to elicit a potent release of calcium from intracellular sources. The direct effects of DLS on MIP-1 $\alpha$, MIP-1 $\beta$ and RANTES induced calcium mobilization were evaluated on CEM.NKR ${ }^{\mathrm{R}}$-CCR5 cells labeled with Fura-2AM. MIP-1 $\alpha(60 \mathrm{nM})$, MIP-1 $\beta$ (60nM)and RANTES (10nM) caused a significant increase in intracellular calcium and this calcium flux was markedly inhibited in a dose dependent fashion by DLS (Figure 2). DLS inhibition of calcium release was seen more clearly with RANTES than with MIP-1 $\alpha$ and MIP-1 $\beta$. Interestingly, higher concentrations of DLS were typically needed to observe a reproducible effect on chemokine-induced intracellular calcium mobilization. TAK779 was able to almost completely block the binding of all three chemokines at concentrations less than $2 \mu \mathrm{M}$ (data not shown), demonstrating TAK779 to be a much more potent and selective antagonist than the GHS-R1a antagonist being examined here. 

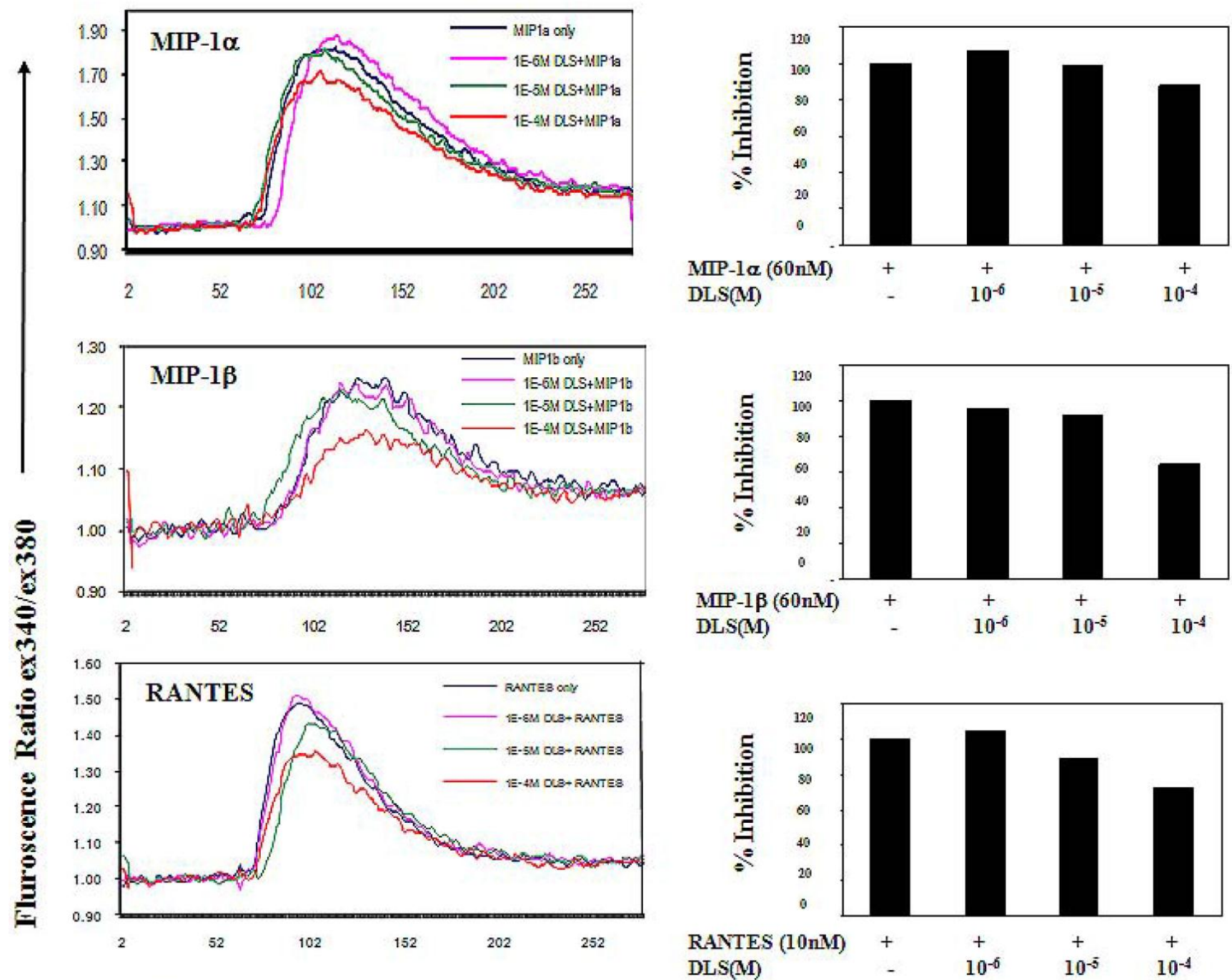

Timeseconds

Figure 2. D-Lys3-GHRP-6 inhibits SDF-I-, MIP-I $\alpha$-, MIP-I $\beta$ - and RANTES-induced intracellular calcium release from CEM-CCR5 cells. CEM-CCR5 cells were loaded with Fura-2-AM dye, washed, treated with different concentration of DLS for 20 minutes and I.5 ml cells used to read for calcium release after addition of chemokine in luminescence spectrometer. Each graph shows the $340 \mathrm{~nm} / 380 \mathrm{~nm}$ excitation ratio at $509 \mathrm{~nm}$ absorption. It shows CEM-CCR5 cells' calcium release after addition of MIP-I $\beta$ (60nM), MIP-I $\alpha(60 \mathrm{nM})$ and RANTES $(I 0 \mathrm{nM})$. The data reveals that, DLS partially inhibits MIPI $\beta$, MIPI $\alpha$ and RANTES induced calcium release (range of $10-40 \%$ inhibition).

\section{DLS inhibits MIP-I $\alpha$, MIP-I $\beta$ and RANTES binding}

To determine if DLS blocks CCR5 receptor, we utilized a whole cell ligand binding assay with a biotinylated form of MIP- $1 \alpha$, MIP-1 $\beta$ and RANTES, followed by binding of an avidin-fluorescein isothiocyanate (FITC) conjugate, and subsequent examination by using flow cytometric analysis. Upon DLS treatment the percent maximal binding of MIP- $1 \alpha$ and RANTES in the CEM.NKR ${ }_{-}$CCR5 cells was reduced reproducibly by up to $40 \%$ in the donors tested but binding of MIP-1 $\beta$ was not dramatically affected (Figure 3) suggesting that DLS may differentially blocks chemokine ligand binding to the CCR5 receptor. As expected, TAK779 was able to almost completely block the binding of all three chemokines at concentrations less than $2 \mu \mathrm{M}$ (data not shown), demonstrating TAK779 to be a much more potent and selective antagonist than the GHS-R1a antagonist being examined here. 

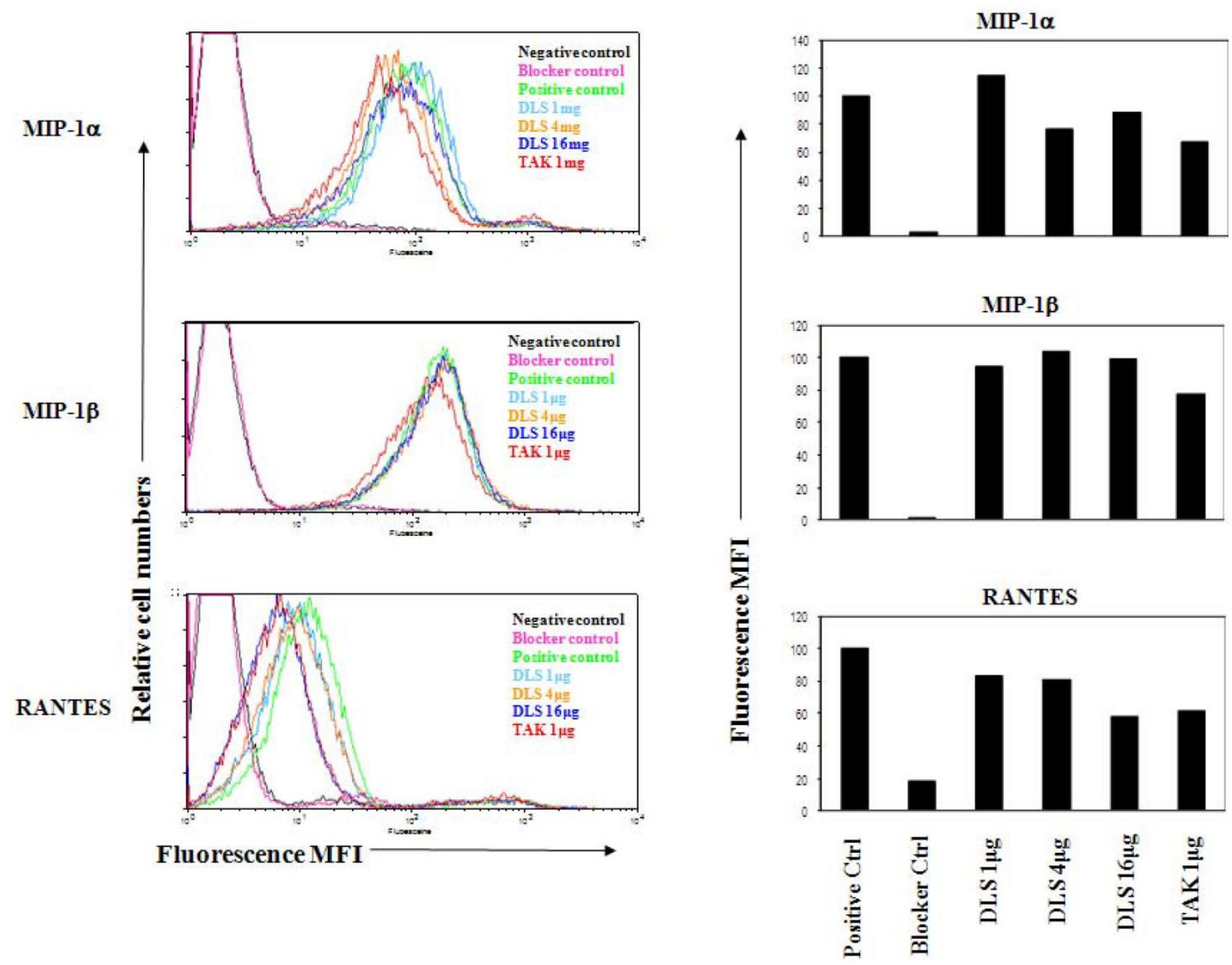

Figure 3. DLS selectively blocks chemokine ligand binding to receptor-positive cells. $25 \mu \mathrm{lof} 4 \mathrm{million} / \mathrm{ml}$ cells were incubated with or without different amount of DLS (I/4/16 $\mu \mathrm{g}$ ) or TAK779 (for CCR5 inhibition, I $\mu \mathrm{g}$ ) for 30 minutes at $4^{\circ} \mathrm{C}$. Add $20 \mathrm{ml}$ of biotinylated-chemokine and incubate for $\mathrm{Ihr}$ at $4^{\circ} \mathrm{C}$. After incubation, $20 \mu \mathrm{l}$ of avidin-fluoresceine was added to the wells and then the plate was incubated for 30 minutes at $4^{\circ} \mathrm{C}$. The cells were subsequently washed with IxRDF b/f. Fix cells with $2 \%$ PFA and run on FACScan. Graph shows fluorescence intensity for each treatment. Results reveal that, DLS blocks binding of MIP-I $\alpha$ and RANTES with $20 \%-40 \%$ range. DLS does not affect MIP-I $\beta$ binding.

\section{DLS inhibits chemokine-mediated signaling in CCR5-transfected 3T3 cell lines}

3T3.T4.CCR5 cells were grown overnight and then pretreated with DLS $(20 \mu \mathrm{M})$ or the CCR5 specific antagonist, TAK779 $(2 \mu \mathrm{M})$ for 30 minutes at $37^{\circ} \mathrm{C}$ after which $10 \mathrm{nM}$ of MIP-1 $\beta$ or RANTES were added to cultures. The cells harvested in RIPA after washing with cold PBS at the indicated times. The results (Figure 4) reveal that DLS partially blocks RANTES-induced ERK activation in 3T3.T4.CCR5 cells. Surprisingly, MIP-1 $\beta$-induced ERK activation was not influenced by DLS using this cell line. Tak779 at $2 \mu \mathrm{M}$ only demonstrated a $20-30 \%$ inhibition of ERK phosphorylation in these CCR5 expressing cells.

\section{DLS decreases HIV-I propagation in vitro in activated PBMCs}

Given the ability of DLS to partially abrogate chemokine binding and signaling, we sought to determine if DLS could exhibit any inhibitory effects in HIV-1 infectivity in human PBMCs. Activated PBMCs treated with DLS or the chemokine receptor antagonist TAK779 for 30 minutes at $37^{\circ} \mathrm{C}$. HIV-1 $1_{\text {Ba-L }}$ (CCR5 tropic) was added to the cultures at $37^{\circ} \mathrm{C}$ for 3 hours. The non-bound virus was washed off the treated cells and the cells were cultured for 3, 6 or 9 days to examine HIV-1 $1_{\text {Ba-L }}$ viral output by the infected cells. Supernatants were collected from each well at day 3, 6 and 9 and p24 levels were measured using ELISA assays. The results reveal that DLS inhibits R5 tropic HIV-1 $1_{\text {Ba-L }}$ propagation in PBMCs (Figure 5). 
A
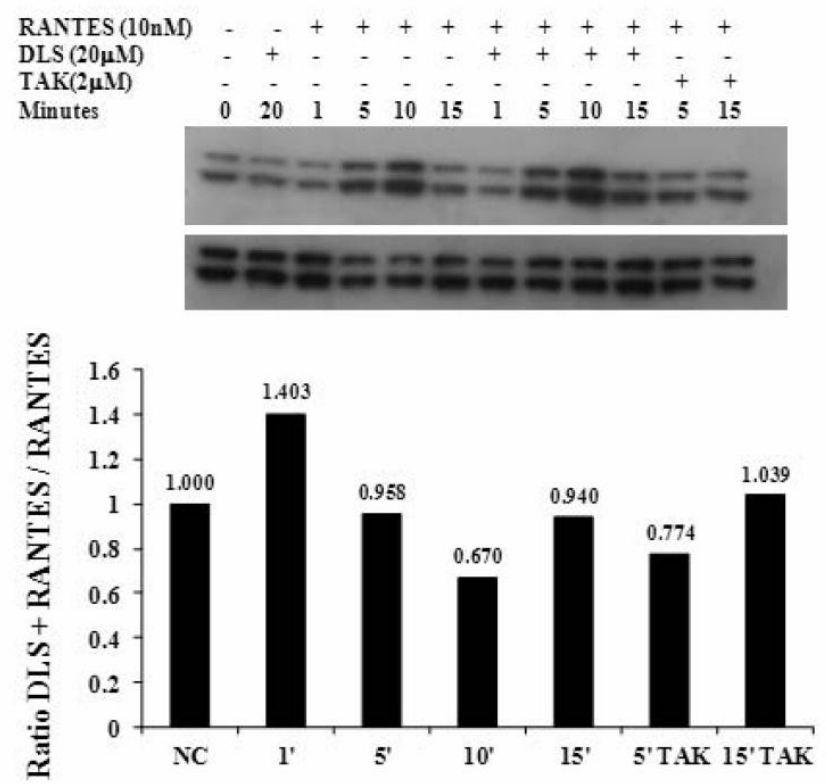

B
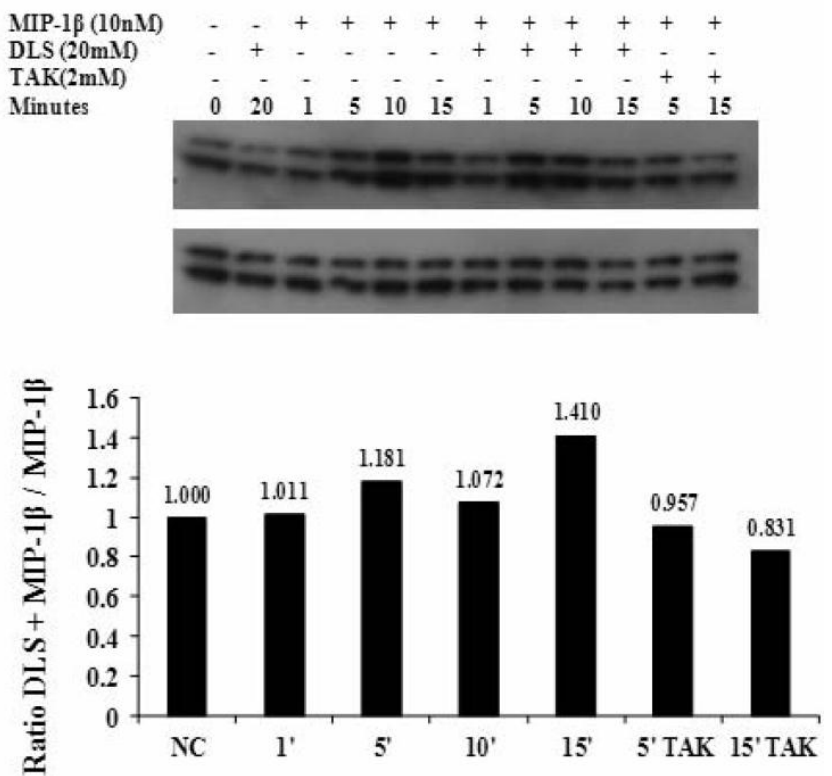

Figure 4. DLS inhibits chemokine- mediated signaling in CCR5-transfected 3T3 cell lines. Approximately 200,000 3T3.T4.CCR5 cells were grown overnight per well in 6-well plate. On the following day, the media was replaced with $2 \mathrm{ml}$ of serum free medium. After 2-3 hrs, DLS $(20 \mu \mathrm{M})$ or the CCR5 specific antagonist, TAK779 $(2 \mu \mathrm{M})$, were added to respective wells, incubated for 30 minutes at $37^{\circ} \mathrm{C}$ after which IOnM of RANTES (A) or MIP-I $\beta$ (B) was added to indicated wells. The cells harvested in RIPA after washing with cold PBS at the indicated times. $30 \mu \mathrm{g}$ of protein run in $4-20 \%$ Bis-Tris gel, transferred and probed with mouse anti-pERK antibody (upper panel) stripped and again probed with rabbit anti-total ERK antibody (lower panel). The results reveal that DLS partially blocks RANTES induced ERK activation but surprisingly does not block MIP-I $\beta$-induced ERK activation in 3T3.T4.CCR5 cells.

Figure 5. DLS decreases HIV-I propagation in vitro in activated PBMCs. Activated PBMCs were washed and treated with DLS or TAK779 for 30 minutes at $37^{\circ} \mathrm{C}$. Add IOng (p24) of HIV-IBa-L (CCR5 tropic) per one million cells in one $\mathrm{ml}$ medium, incubate at $37^{\circ} \mathrm{C}$ for $3 \mathrm{hrs}$. Wash cells to remove unbound virus and resuspended to a concentration of 0.5 million cells per one $\mathrm{ml}$ medium, add antagonists and plate in triplicate wells in 24-well plate and incubate at $37^{\circ} \mathrm{C}$. Collect supernatant from each well at day 6 and 9 and measure p24 level using ELISA. The graphs show \% of p24 level over virus only controls at day $6 \& 9$. The results reveal that DLS inhibits R5 tropic HIV-I propagation in PBMCs.
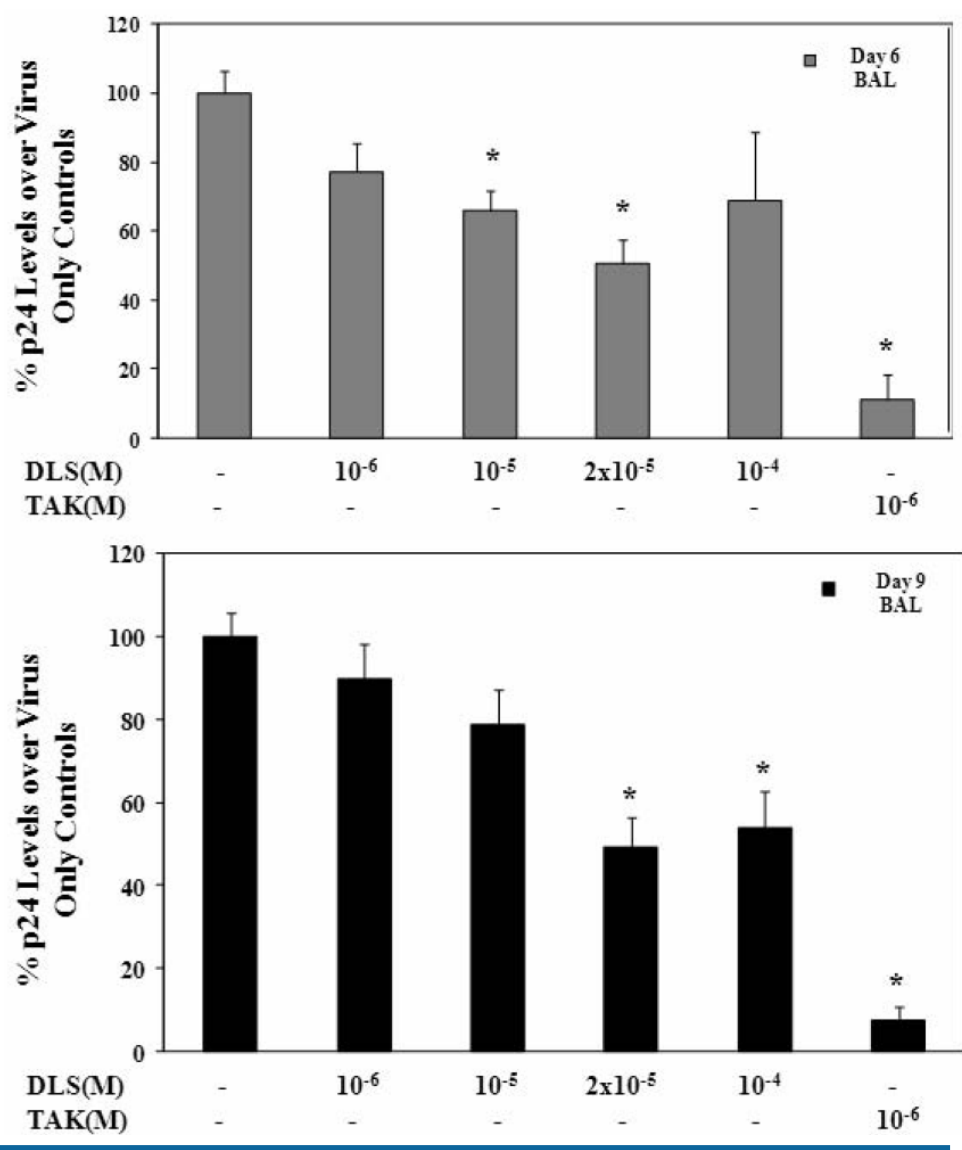


\section{Discussion}

Migration of immune cells to sites of inflammation is a multistep process mediated largely by interactions of various chemokines to their $G$ protein linked seven transmembrane receptors $[1,14]$. CCR5 and CXCR4 are the principal chemokine receptors critical for cellular migration and are used in association with CD4 by human immunodeficiency virus (HIV) to enter its target cells. These co-receptors are important determinants of viral tropism, pathogenesis and virulence and are widely believed to be important drug targets to prevent HIV infections [4]. A number of CCR5 inhibitors like SCH417690, UK427857, GSK873140, PRO140 are currently being tested for their efficacy against R5 tropic HIV viruses [10]. The synthetic peptidyl compound D-[Lys3]GHRP-6 (H-His-D-Trp-D-Lys-Trp-D-Phe-Lys-NH2) is currently believed to be a selective antagonist of ghrelin receptors (GHS-R). However, no studies exist on the potential interaction of this compound with other clinically relevant GPCRs of chemokine family. We have discovered that DLS can also modestly antagonize the binding and signaling of CCR5 chemokine receptor, more potently acting on RANTES activity through CCR5 (Figure 6). DLS has been utilized experimentally in rodent models without any adverse side effects and repeated administration have been found to reduce body weight in obese mice and improve their glycaemic control and insulin resistance [15]. Furthermore, DLS reduced the size of abdominal fat pads without affecting the muscle mass in these mice. There is accumulating clinical evidence linking currently used HIV inhibitors to the pathogenesis of insulin resistance, dyslipidemia, lipodystrophy and atherosclerosis in AIDS patients [16]. Thus DLS along with its potential HIV inhibitory properties may attenuate the metabolic effects associated with HAART therapy in AIDS patients. Additionally, DLS does not affect food intake in the fed state when circulating ghrelin levels are low, allowing for its potential use post-prandially.

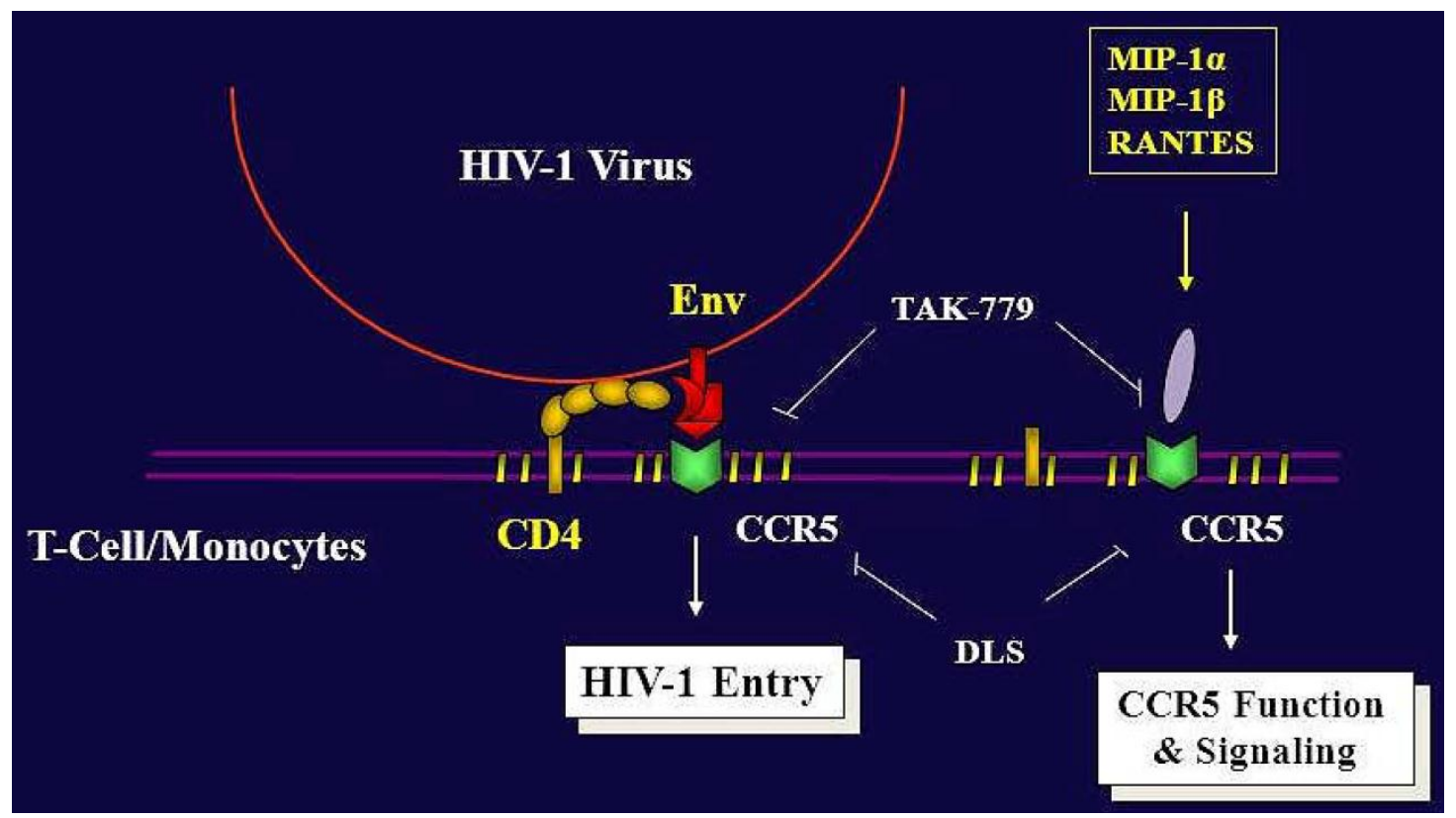

Figure 6. Summary of DLS and TAK779 activities on HIV-I propagation and CCR5 Function. While the current and most efficient treatment modalities for the treatment of HIV-I+ patients include reverse transcriptase and protease inhibitors, viruses are now developing resistance to one or more agents. Despite the efficacy of these agents, there is still dire need to discover new anti-HIV agents to inhibit viral infectivity. CXCR4 and CCR5 are the major co-receptors for HIV-I entry into the CD4 positive cells. Thus, it would appear that chemokine receptors, more specifically here CCR5, are attractive targets to block HIV-I binding, fusion and infectivity. Several potent chemokine receptor antagonists have been developed and are being utilized in clinical studies. TAK779 is a very selective CCR5 blocking agent and has been shown to block HIV-I entry through CCR5-bearing cells and also blocks CCR5 function and signaling. We have found that the GHS-R I a antagonist, DLS, exhibits some modest blocking effects on CCR5 ligand binding and signaling, with the greatest effects being observed on RANTES binding and activity. Moreover, DLS can inhibit CCR5-trophic HIV-I infectivity in CCR5+ immune cells, although it is significantly less potent than the CCR5 selective antagonist, TAK779, which is currently being utilized in clinical trials. While DLS may possess some modest antagonist activity for CCR5, the primary finding focused on in this manuscript is that DLS, initially thought to be a highly selective antagonist for the gh relin receptor, GHS-R la, appears to be promiscuous and may have some effects on other G-protein coupled receptors (GPCRs) such as chemokine receptors. 
Therapy for HIV-1+ subjects includes reverse transcriptase and protease inhibitors. These inhibitors have achieved sustained suppression of viral replication in HIV-1-infected individuals, although these viruses are now developing resistance to one or more agents. These inhibitors are costly and require long term use. Despite the efficacy of these agents, there is still dire need to discover new anti-HIV agents to inhibit viral infectivity. CXCR4 and CCR5 are the major co-receptors for HIV-1 entry into the CD4 positive cells. Several of the SNPs and specific deletions in CXCR4 and CCR5 genes have been shown to result in a resistance or slower progression of HIV-1 infection without any substantial immune (functional) defect in humans. Thus, it would appear that chemokine receptors, more specifically CXCR4 and CCR5, are attractive targets to block HIV-1 binding, fusion and infectivity (Figure 6). TAK779 is a very selective CCR5 [10] blocking agent. Surprisingly, this antagonist has been discontinued after phase I trial, because of severe toxicities [5].

\section{Acknowledgements}

We would like to thank Mr. Gary Collins for his assistance in the completion of this work. This work was supported by the Intramural Research Program of the National Institute on Aging, National Institutes of Health.

\section{Authors' contributions}

All authors read and approved the final manuscript. KP, VDD, JHL, JWK, EMS and DN performed the cell culture and isolation, flow cytometric analysis and ligand binding assays. KP performed all of the HIV infection and calcium mobilization assays. KP, JHL and JWK performed all of the Western blot analyses. KP, VDD, DZ and DDT played a role in the planning and design of the studies. KP, VDD, EMS, $\mathrm{DN}$ and DDT played a role in the writing and editing of the manuscript.

\section{Abbreviations}

DLS, [D-Lys3]-Growth Hormone Releasing Peptide-6; FITC, fluorescein isothiocyanate; GPCRs, G-protein coupled receptors; GHRP-6, Growth Hormone Releasing Peptide-6; GHS-R, Growth Hormone Secretagogue Receptor; PBMCs, peripheral blood mononuclear cells; HIV, human immunodeficiency virus.

\section{Conflict of Interest}

The authors have declared that no conflict of interest exists.

\section{References}

1. Miyasaka M, Tanaka T: Lymphocyte trafficking across high endothelial venules: dogmas and enigmas. Nat Rev Immunol 2004, 4:360-370.

2. Balkwill F: Cancer and the chemokine network. Nat Rev Cancer 2004, 4:540-550.

3. Cascieri MA, Springer MS: The chemokine/chemokinereceptor family: potential and progress for therapeutic intervention. Curr Opin Chem Biol 2000, 4:420-427.

4. Castagna A, Biswas P, Beretta A, Lazzarin A: The appealing story of HIV entry inhibitors : from discovery of biological mechanisms to drug development. Drugs 2005, 65:879-904.

5. Lai $\mathrm{WH}$, Huang L, Chen $\mathrm{CH}$ : HIV entry inhibitors: progress in development and application. Yao Xue Xue Bao, 2010;45:131-140.

6. Howard AD, Feighner SD, Cully DF, Arena JP, Liberator PA, Rosenblum CI, Hamelin M, Hreniuk DL, Palyha OC, Anderson J, et al: A receptor in pituitary and hypothalamus that functions in growth hormone release. Science 1996, 273:974-977.

7. Kojima M, Kangawa K: Ghrelin: structure and function. Physiol Rev 2005, 85:495-522.

8. Smith RG: Development of growth hormone secretagogues. Endocr Rev 2005, 26:346-360.

9. Rubin JB, Kung AL, Klein RS, Chan JA, Sun Y, Schmidt K, Kieran MW, Luster AD, Segal RA: A small-molecule antagonist of CXCR4 inhibits intracranial growth of primary brain tumors. Proc Natl Acad Sci U S A 2003, 100:13513-13518.

10. Baba M, Nishimura O, Kanzaki N, Okamoto M, Sawada H, Iizawa Y, Shiraishi M, Aramaki Y, Okonogi K, Ogawa Y, et al: A small-molecule, nonpeptide CCR5 antagonist with highly potent and selective anti-HIV-1 activity. Proc Natl Acad Sci U S A 1999, 96:5698-5703.

11. Gartner S, Markovits P, Markovitz DM, Kaplan MH, Gallo RC, Popovic M: The role of mononuclear phagocytes in HTLV-III/LAV infection. Science 1986, 233:215-219.

12. Dixit VD, Schaffer EM, Pyle RS, Collins GD, Sakthivel SK, Palaniappan R, Lillard JW, Jr., Taub DD: Ghrelin inhibits leptinand activation-induced proinflammatory cytokine expression by human monocytes and T cells. J Clin Invest 2004, 114:57-66.

13. Nguyen $\mathrm{DH}$, Taub D: Cholesterol is essential for macrophage inflammatory protein 1 beta binding and conformational integrity of CC chemokine receptor 5. Blood 2002, 99:4298-4306.

14. Campbell DJ, Kim CH, Butcher EC: Chemokines in the systemic organization of immunity. Immunol Rev 2003, 195:58-71.

15. Asakawa A, Inui A, Kaga T, Katsuura G, Fujimiya M, Fujino MA, Kasuga M: Antagonism of ghrelin receptor reduces food intake and body weight gain in mice. Gut 2003, 52:947-952.

16. Kino T, Chrousos GP: AIDS-related insulin resistance and lipodystrophy syndrome. Curr Drug Targets Immune Endocr Metabol Disord 2003, 3:111-117. 